\title{
AC 2007-1777: FINANCIAL ENGINEERING: THE SAVIOR OR END OF ENGINEERING ECONOMY?
}

\section{Joseph Hartman, Lehigh University}

Joseph C. Hartman is an Associate Professor in the Department of Industrial and Systems Engineering at Lehigh University, holds the George Kledaras Endowed Chair, and serves as Department Chair. He received his Ph.D. (1996) and M.S. (1994) in Industrial Engineering from the Georgia Institute of Technology and B.S. in General Engineering from the University of Illinois at Urbana-Champaign (1992). His research interests are in economic decisions analysis and dynamic programming. His undergraduate textbook, "Engineering Economy and the Decision-Making Process," was released in the summer of 2006. He is an active member of ASEE, IIE, and INFORMS and currently serves as Editor of "The Engineering Economist" and the Senior Vice President of Publications on the IIE Board of Trustees.

\section{David Enke, University of Missouri}




\title{
Financial Engineering: The Savior or End of Engineering Economy?
}

\begin{abstract}
There has been a major push into the field of "financial engineering" in the last few years, although the field has been growing in both research and education for over two decades. Initially, the field was described as the design (engineering) of financial products (i.e., derivatives), but now it has a much broader interpretation, including the application of advanced tools (i.e., mathematical programming or stochastic processes) to the analysis of financial instruments with the goal of increasing profits and/or decreasing risk. As this field has grown, so have the employment opportunities for engineers in the financial sector, including jobs as analysts with investment banks, hedge funds, brokers, and insurance companies. This has resulted in a number of schools offering graduate programs in Financial Engineering (or similar areas, such as Computational Finance, Mathematical Finance, Quantitative Finance, and Analytical Finance). Inevitably, and in our experience, demand is growing at the undergraduate level for such a major. If offered, it would seem natural that the degree would come from an industrial engineering, engineering management, operations research or systems engineering department. We examine how schools are addressing this issue and also ponder the requirements for such a degree and how it may or may not impact the "traditional" offering of engineering economy.
\end{abstract}

Introduction: Trends and Needs

Engineering economy is a mature field, which draws its roots back to the turn of the century. Broadly defined, engineering economy is concerned with the time value of money and economic decision analysis. Studies are generally tied to capital budgeting decisions and may utilize decision criteria, such as present worth or internal rate of return, sensitivity analysis, simulation, and even mathematical programming (advanced studies) in order to make investment decisions.

The newer field of "financial engineering" has been growing over the past few decades in both educational offerings and research. Broadly defined, financial engineering is the application of advanced mathematical and engineering tools, such as mathematical programming, stochastic processes, or simulation, to the analysis of financial instruments, primarily financial derivatives. In essence, financial engineers attempt to either design new over-the-counter financial products that define and manage unique risk and return between two parties, or simply take existing securities and engineer new ways to hedge current positions. Commensurate with the goals of most financial firms, the aim of the analysis is to increase returns, reduce risk, and/or increase efficiency.

With the growing interest of financial firms, including investment banks, brokers, and insurance companies to hire engineers for jobs traditionally filled by accounting and finance majors, there appears to be a growing interest for engineering departments (most likely industrial and/or systems) to provide more education in the areas of financial risk management. This has fueled the growth in financial engineering. 
A number of engineering colleges offer M.S. degrees in financial engineering (e.g., Columbia, Cornell, Michigan, California-Berkeley, among others) or related areas such as analytical finance or computational finance. Numerous programs are also beginning to offer graduate certificates in financial engineering (e.g., Missouri-Rolla, Stevens Institute of Technology), thereby testing the waters for this growing field. These programs can be housed in an engineering school or provided jointly with finance and mathematics departments. While financial engineering education has generally been restricted to the graduate level, as it relies on higher-level mathematics (stochastic calculus, partial differential equations, and stochastic programming, for example), there are programs at the undergraduate level. Princeton University offers an undergraduate degree through its Operations Research and Financial Engineering department, while Columbia University offers an undergraduate degree in Operations Research: Financial Engineering.

With the growth of these new courses and curriculums in financial engineering, it is believed that there has been a decline in the offerings of engineering economy. As noted by Fraser ${ }^{1}$ nearly all Industrial Engineering programs required a course in engineering economics. However, offerings outside the departments are not always required. For example, only industrial and civil engineers typically must take engineering economy. At Georgia Tech, non-IE majors take a 2hour online version with microeconomics. Despite being a section on the FE exam, it appears that the desire to reduce the number of hours needed to attain a degree has led to the elimination of engineering economy from the curriculum of many engineering majors.

Thus, on the surface, it appears that engineering economy is a bit on the decline while financial engineering is on the rise. In this paper, we grapple this with this issue and try to shed some light on the future of the field.

\section{Examples of Changes in Courses and Offerings}

We illustrate four changes that have occurred that may, or may not, be telling of the future of engineering economics: Northwestern, which has changed its courses but not its degrees; Columbia, which has a new degree; Princeton, which does not offer a traditional industrial engineering degree; and Missouri-Rolla, which has a certificate program.

Northwestern University no longer offers a course in "engineering economy". Rather, they offer a course in "Economics and Finance for Engineers" which is described as "Principles of corporate finance; financial decisions of firms; value; risk and return; investment and capital budgeting decisions under certainty and uncertainty; performance evaluation." "Clearly, this is a mix of topics that would be found in corporate finance and traditional engineering economy courses. However, not all of these topics would be covered in a typical engineering economy course. While engineering economy has at times focused more on project evaluation through economic analysis, considering the effects of depreciation, taxes, and inflation on the time-value of project cash flows, corporate finance topics are now shifting the focus more towards capital budgeting. Coverage now includes more emphasis on the management of the "investment pool", including aspects of portfolio theory. This has naturally lead to risk management, and the general area of financial engineering. 
After completing this course and another in stochastic processes, students at Northwestern can take "Intro to Financial Engineering," described as "Financial markets, derivative securities, risk management, mathematical models in finance. Foreign exchange, debt, equity, commodity markets. Investing, trading, hedging, arbitrage. Forwards, futures, options, swaps, exotic derivatives. Models of price dynamics, binomial model, introduction to Black-Scholes theory and Monte Carlo simulation."2 Clearly, these topics are not found in engineering economy courses and traditionally only taught in a finance department.

Columbia University offers an introductory course in "Industrial Economics" which can be described as a traditional engineering economy course. Furthermore, they follow that course with advanced courses titled "Industrial Budgeting and Financial Control" and "Advanced Engineering and Corporate Economics." However, they also offer a course called "Introduction to Financial Engineering" described as "Introduction to investment and financial instruments via portfolio theory and derivative securities, using basic operations research/engineering methodology. Portfolio theory, arbitrage; Markowitz model, market equilibrium, and the capital asset pricing model. General models for asset price fluctuations in discrete and continuous time. Elementary introduction to Brownian motion and geometric Brownian motion. Option theory; Black-Scholes equation and call option formula. Computational methods such as Monte Carlo simulation." 3 The course carries a stochastic processes course prerequisite and follows the industrial economics course in the undergraduate sequence. This course has four follow-on courses dealing with pricing (continuous and discrete time), data analysis, and a project course.

Princeton does not have an engineering economy course but offers "Introduction to Financial Engineering," described as: "Financial engineers design and analyze products that improve the efficiency of markets and create mechanisms for reducing risk. This course introduces the basics of financial engineering: the notions of arbitrage and risk-neutral probability measure are developed in the case of discrete models; Black-Scholes theory is introduced in continuous-time models, and interest rate derivatives and the term structure of interest rates are discussed."4 This course is followed by a number of courses on risk management and economics of uncertainty.

Other examples also exist. While the Engineering Management and Systems Engineering department at the University of Missouri-Rolla still teaches various introductory courses in engineering economy, both at the undergraduate and graduate level, they have recently changed the name of their graduate level "Advanced Engineering Economy" course to "Financial Risk Management." The new course now covers "Techniques and methods for managing financial risk, including portfolio theory, Monte Carlo methods, ARIMA, time series forecasting, Valueat-Risk, stress testing, extreme value theory, GARCH and volatility estimation, random variables and probability distributions, real options, decision trees, utility theory, statistical decision techniques, and game theory." While this course was modified in part to better fit within the department's new Graduate Certificate in Financial Engineering, it also now provides coverage of new advanced topics in engineering economics and financial risk management.

For some programs, similar changes are also being made since many of the previous advanced topics (such as probabilistic approaches to cash flows and decision tree analysis) are now being introduced at the introductory level. In fact, it is difficult to even find an advanced engineering 
economy textbook, while textbooks covering topics on financial risk management are on the rise, even though they begin with many of the same concepts and techniques.

Impact on Engineering Economy

Engineering economy has always been a multidisciplinary field as it is concerned with issues in engineering and business (economics and finance). As the field of financial engineering continues to grow, it is only natural that engineering and business ties become stronger. Thus, it is an opportune time for engineering economy to become more inclusive such that it can provide the base to this new field while still attending to the traditional needs of engineering.

As an introductory course, the basics of the time-value-of-money and capital budgeting cannot change. However, it may be necessary to include more exposure to financial topics, such as financial statements and instruments (stocks, bonds, and simple derivatives). This may ultimately lead to more two-course sequences. An advanced engineering economy course would be for those students pursuing engineering careers, with topics including advanced methods for analysis under risk and uncertainty (simulation and real options analysis) with applications in equipment replacement and capacity planning. An advanced course in financial engineering would include topics on options pricing and portfolio optimization. For those curriculums that cannot afford three courses, two courses may suffice, but applications must be mixed. For example, a discussion of the Black-Scholes model for options pricing should be followed by its application to a real options-based invest/delay/do-not-invest decision for a manufacturing or distribution facility, followed by alternative forms of analysis (present worth with extensive simulation and sensitivity analysis).

In a sense, it is necessary for the capital budgeting aspects of engineering economy to truly cover capital budgeting, along with many of its risk-based requirements and consequences. Currently, coverage of capital budgeting within engineering economy often simply involves a short discussion of the investment pool, the after-tax cost of capital for stocks and bonds, and a discussion of the weighted average cost of capital and its use for setting minimum acceptable rates of return. Any discussion of risk and return is often referenced only to project cash flows, and their effect for potentially reversing the project investment decision. Capital budgeting must now provide more coverage concerning the risk of the investment pool itself. It must now consider the risk and return of the stocks and bonds within the investment pool portfolio, along with the use of derivative securities for managing the portfolio's risk. If done correctly, this will provide future engineers the skills they need, while also providing a nice bridge and introduction to the field of financial engineering.

\section{Conclusions}

While it is unclear to us who coined the term "engineering economy," it is clear to many of us in the field that it could have equally been termed "finance for engineers." The reality is that engineering economy is concerned with the time value of money, generally applied to problems faced by engineers. The growth of the financial engineering field will generally define a broader set of problems which engineers may be exposed to - clearly if they are hired into a financial company. That is, graduating engineers may someday be equally likely to face a problem of 
whether to invest in a new plant or not as he or she is to face the problem of optimizing a portfolio of stocks and bonds, or dealing with interest rate and exchange rate uncertainties. The question is whether this impacts engineering economy education. The answer, naturally, is yes. As engineering economy educators, we must be aware of these changes.

While this discussion has focused on possible changes in engineering economy education, one must also consider the future of research in this area. Combining engineering economy research in capital investment analysis and the advanced analysis of financial instruments leads to numerous, exciting opportunities. Clearly, there have already been great advances in real options analysis (the application of financial options analysis to capital investments) and portfolio theory (application of portfolio theory to capital investment decisions). It would appear that there are even greater opportunities when one considers not only moving tools from one realm (engineering) to the problems in another (finance), but rather, their merger. For example, the decisions of when, where, and what size to build an electricity generation (energy) plant, in addition to what technology (i.e., coal, nuclear, natural gas) has generally been an engineering decision. However, with mature energy trading markets, these decisions cannot be completely separated from market mechanisms, globalization, and economic forces. The integration of these issues in the analysis makes for a wonderful marriage of financial engineering and engineering economics. These opportunities should continue to grow in time.

\section{References}

1. Fraser, Jane M., "Benchmarking IE Programs," ASEE Annual Conference Proceedings, Portland, OR, June 2005.

2. Information accessed from http://www.iems.northwestern.edu/content/courses.asp, January, 2007.

3. Information accessed from http://www.ieor.columbia.edu/pages/undergraduate/financial_eng/index.html, January, 2007.

4. Information accessed from http://www.princeton.edu/pr/catalog/ua/05/461.htm, January, 2007.

5. Information accessed from http://syseng.umr.edu/graduateprograms/sysengms.html, January, 2007. 